\title{
Case report of dissection of the right coronary artery due to uncontrolled rotational movement of the guiding catheter: A twist in the story
}

\author{
AlaAbu Dogosh*, Jean Marc Weinstein, Doron Zahger ${ }^{1}$ and Carlos Cafri \\ Department of Cardiology, Soroka University Medical Center and Faculty of Health Sciences, Ben-Gurion University of the Negev, Israel
}

\section{Introduction}

Catheter-induced coronary artery dissection is a rare complication with potentially life-threatening consequences. It has been described in less than $0.1 \%$ of patients undergoing coronary angiography [1-3]. Technical reasons (type of catheter, catheter position, deep intubation) as well an anatomical/histological predisposition (ostial disease, vessel orientation, vessel size, type of collagen fibers) contribute to its development [4-7]. Contact between the tip of the catheter and the arterial wall promoting intimal disruption and subsequent penetration of contrast during the injection is the basic substrate for this phenomenon.

We present a case of dissection of the right coronary artery (RCA) developing during contrast injection and created by spontaneous twisting of the guiding catheter tip on itself due to rotatory tension forces induced by tortuosity of the innominate artery.

\section{Case report}

A 50-year-old male smoker presented to the emergency department with one hour of severe chest pain. An acute inferior wall ST-elevation myocardial infarction (MI) was diagnosed. The patient was treated with aspirin $300 \mathrm{mg}$, prasugrel $60 \mathrm{mg}$ and heparin $5000 \mathrm{IU}$ intravenously and taken immediately to the catheterization laboratory. The procedure was performed via the right radial artery. Passage of the catheters from the innominate artery into the ascending aorta was difficult due to tortuosity of the artery. Diagnostic angiography of the left coronary artery demonstrated non-obstructive disease. The right coronary artery (RCA), the presumed culprit vessel, was approached with a6Fright Judkins 4 guiding catheter (Vista BriteTip ${ }^{\circ}$, Cordis USA). Difficulty in rotation of the catheter was experienced as a result of friction at the level of the innominate artery. Application of sustained rotational forces eventually enabled engagement of the catheter tip into the RCA. After a quick verification of the catheter position, an injection of contrast was performed, filling the artery and demonstrated a severe stenosis at its distal segment. During the injection, a sudden widening of the arterial borders was seen, due toa spiral dissection. At the end of the injection, the catheter disengaged from the arterial ostium (Figure 1A-1D). Repeated attempts to recannulate the vessel failed due to the torque on the catheter causing it to slip out of the artery immediately after each cannulation. In an attempt to stabilize the system, a coronary wire (Asahi Sion Blue, Intecc USA INC) was advanced into the RCA through the true lumen of the vessel, to a distal position. The wire prevented the rotational tendency of the catheter, allowing an additional injection, which demonstrated severe luminal compromise in the proximal portion of the artery (Figure 2). An Ultimaster ${ }^{\mathrm{m}}$ drug eluting stent (DES) (Terumo, Tokyo, Japan) $3.5 \mathrm{~mm} \times 33 \mathrm{~mm}$ was immediately implanted into the proximal dissected segment of the artery, resulting in reopening of the vessel and closure of the dissection's entry site (Figure 3A). An additional Ultimaster ${ }^{\mathrm{rxt}}$ DES ( $3 \mathrm{~mm} \times 24 \mathrm{~mm}$ ) was then directly implanted into the severe distal stenosis of the RCA (Figure 3B), with an eventual optimal angiographic result and TIMI grade III flow (Figure 4). The patient's chest pain resolved, and his subsequent course was uneventful.

\section{Discussion}

This case represents a rarely reported mechanism of traumatic dissection of the RCA during coronary angiography due to an unpredictable spontaneous movement of the catheter at the time of contrast injection.

Catheter induced coronary dissection is an infrequent and dangerous complication of coronary angiography and intervention, with potential significant consequences. It may lead to acute vessel closure, myocardial infarction, emergent therapies during angioplasty, emergent cardiac surgery, and even death [8].

Catheter tip-induced arterial wall injury and intimal disruption is the basic mechanism causing penetration of contrast into the arterial wall and creation of a false lumen which can promote acute occlusion of the vessel by compression of the true lumen.

Technical as well patient-dependent factors can contribute to this phenomenon. Technically, traumatic dissection can be associated with the morphology, size and function of the catheter. The Amplatzleft catheter, the Extra support guiding catheter ( $\mathrm{C}$ type) and therapeutic rather than diagnostic catheters, have more often been implicated in this complication. Procedural issues such as non-coaxial alignment of the catheter tip within the vessel aggressive manipulation with deep intubation as well the use of extension catheters with deep intubation to improve support during complex PCI, are additional contributing factors [9].

The anatomical and histological characteristics of the artery can influence the risk of dissection. Indeed, incompatible orientation

${ }^{\star}$ Correspondence to: AlaAbu Dogosh, Department of Cardiology, Soroka University Medical Center and Faculty of Health Sciences, Ben-Gurion University of the Negev, Beer-Sheva 84101, Israel, E-mail: ala.dogosh@gmail.com

Received: March 25, 2021; Accepted: April 02, 2021; Published: April 09, 2021 
Dogosh A (2021) Case report of dissection of the right coronary artery due to uncontrolled rotational movement of the guiding catheter: A twist in the story
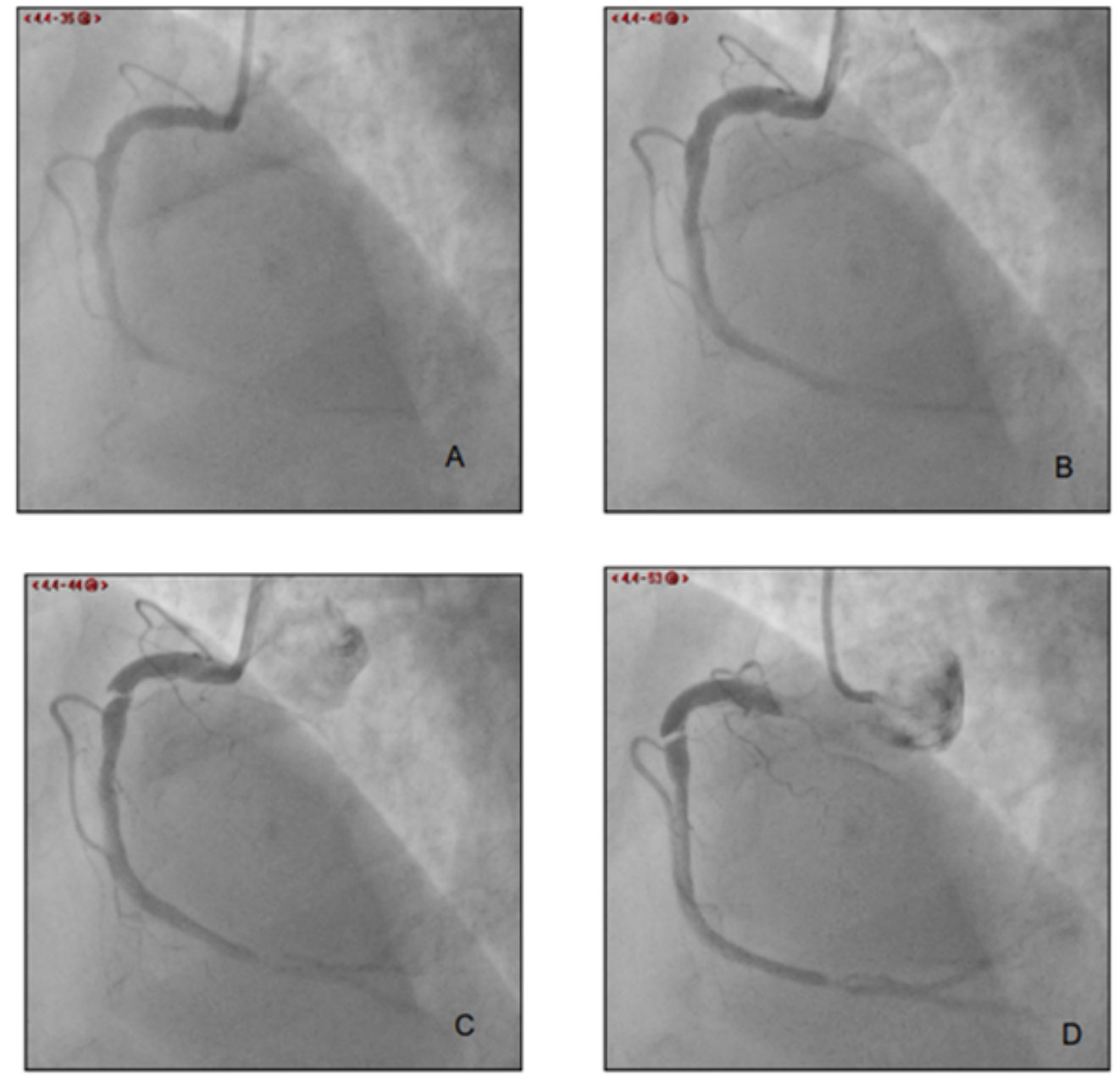

Figure 1A-D. Injection into the RCA showing from $A$ to $D$ the sequence resulting in a spiral dissection of the artery wall.

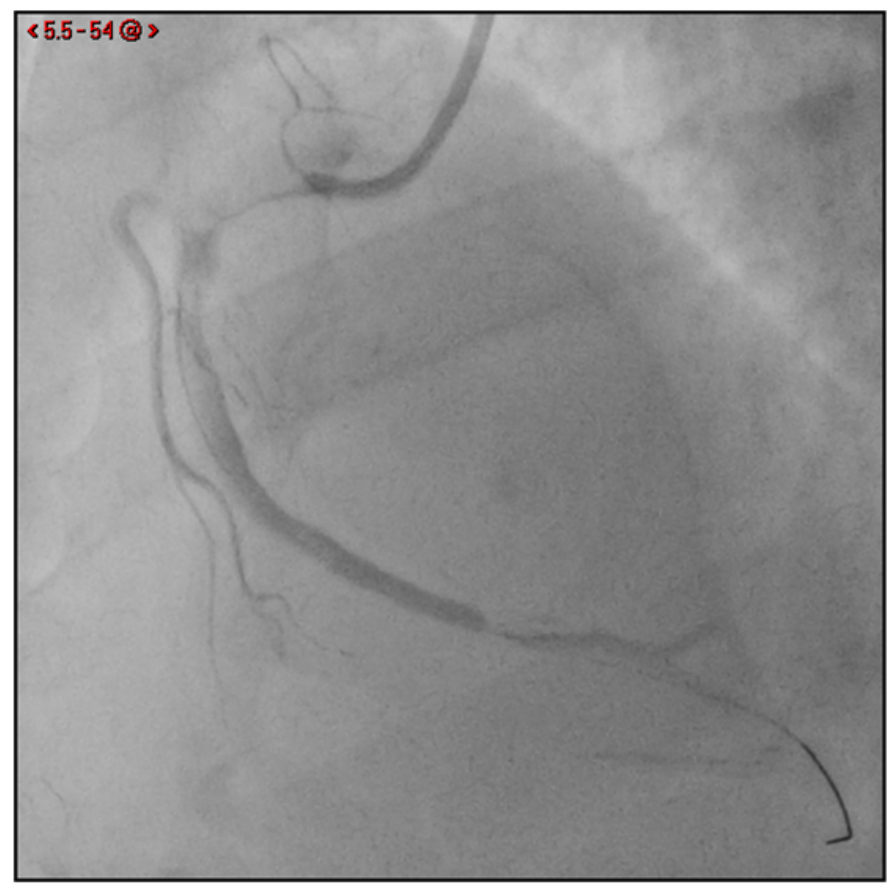

Figure 2. Injection into the RCA after successful wiring demonstrated severe compromise of the lumeninthe proximal and distal portions of the artery. 
Dogosh A (2021) Case report of dissection of the right coronary artery due to uncontrolled rotational movement of the guiding catheter: A twist in the story
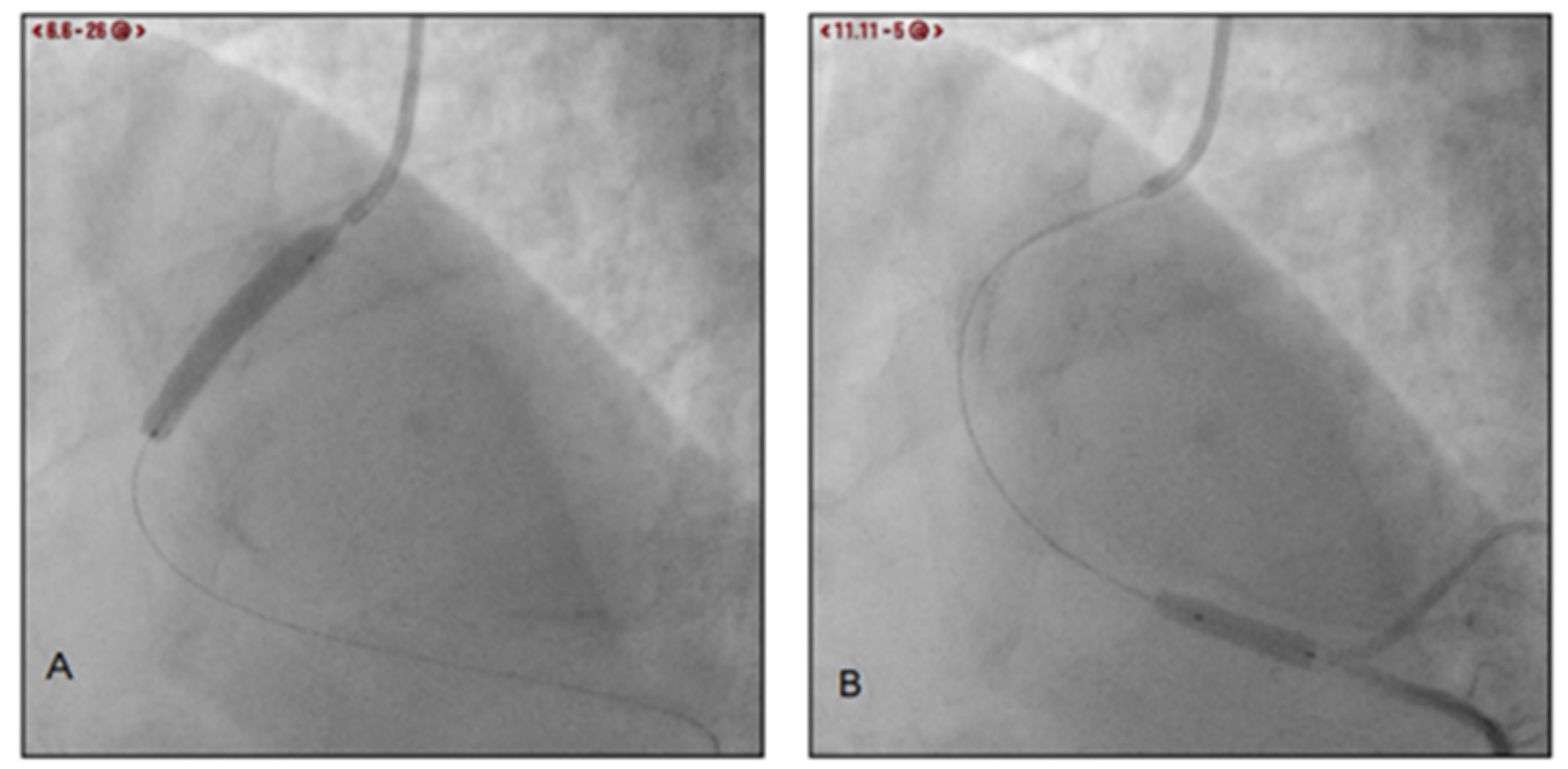

Figure 3. A-B. A. Direct implantation of an Ultimaster ${ }^{\mathrm{TM}}$ drug eluting stent (DES) (Terumo, Tokyo, Japan) $3.5 \mathrm{~mm}$ x $33 \mathrm{~mm}$ into the proximal dissected portion of the RCA, and B. an additional Ultimaster ${ }^{\mathrm{TM}}$ DES $(3 \mathrm{~mm} \times 24 \mathrm{~mm})$ into the severe distal stenosisof the RCA.

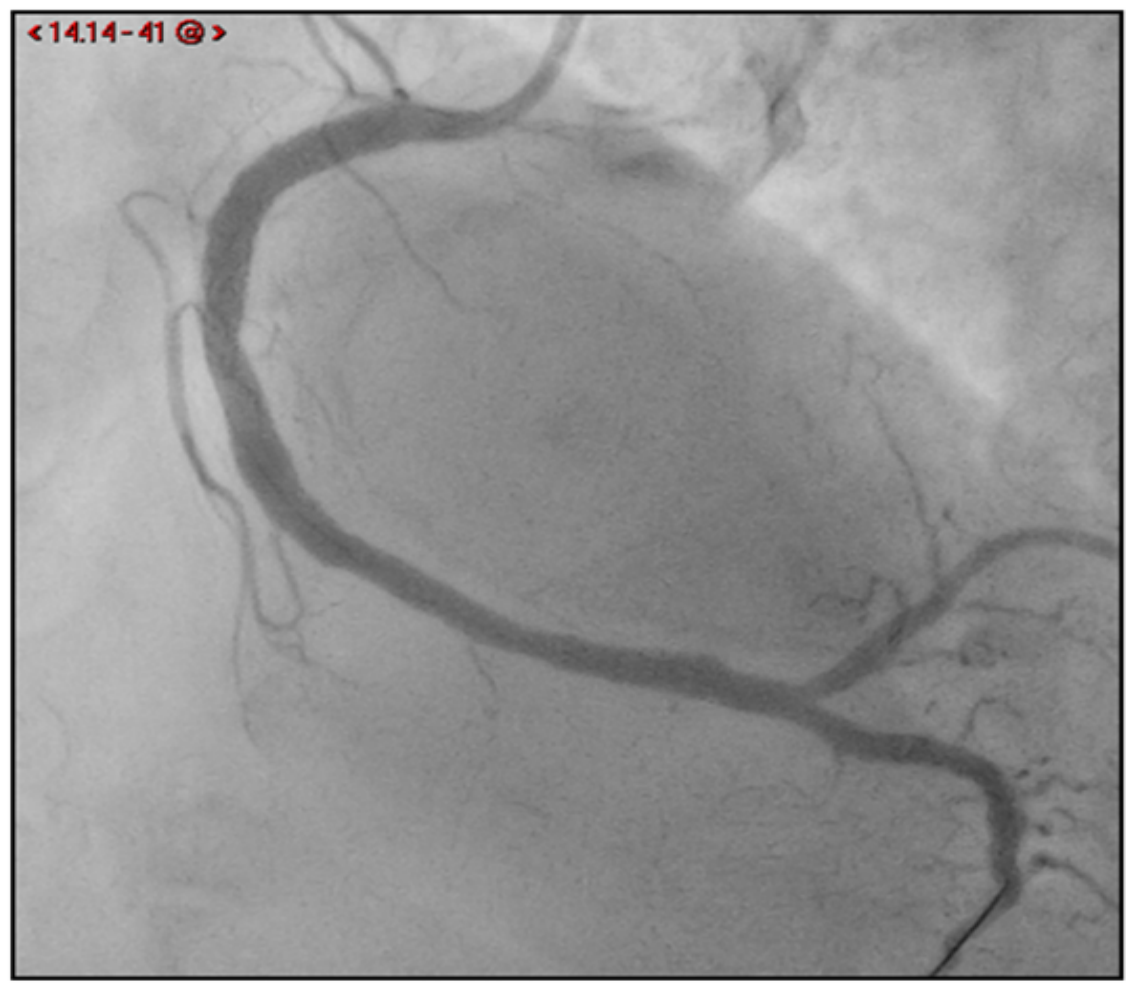

Figure 4. Final injection after PCI demonstrated optimal angiographic result without residual stenosis 
of the catheter with the vessel morphology and diameter, as well the presence of atherosclerotic plaque or spasm at the ostium may promote iatrogenic dissection. Furthermore, the histological properties of the arterial wall are also correlated with this complication. Additionally, spontaneous coronary dissection, an entity associated with multiple vasculopathy, is associated with a $3.4 \%$ incidence of catheter-induced coronary dissection [10].

A fundamental technical issue is the need for continuous observation of the pressure curve during manipulation of the catheter. Pressure damping or ventricularization indicate contact between the tip of the catheter and the arterial wall. Contrast injection when this appears increases the risk of dissection and should be avoided. However, contact between the catheter tip and the wall, as indicated by pressure curve modification does not necessarily occur during the initial injection or at the beginning of an injection. Indeed, change in the position of the catheter tip induced by respiratory variation, cough, arm movements, and the hydraulic forces of the injection can provoke catheter displacement, wall contact and dissection [11].

We present an unusual case of catheter-induced dissection secondary to spontaneous twisting of the guiding catheter during the initial injection. Cannulation of the RCA is usually obtained using a clockwise movement that moves the catheter tip to an anterior position. The torque created by this rotational movement leads toa tendency to recoil in the opposite direction when the operator releases the catheter. When there is tortuosity in the catheter's track, stronger rotational forces need to be applied to advance the catheter and hence the tendency of the catheter to return to its natural position is also stronger. In our case, difficulties in rotating the catheter due to tortuosity in the innominate artery created a strong torque which caused a spontaneous counterclockwise movement of the catheter tip into the arterial wall leading to a dangerous spiral dissection.

Controlled tension release by the operator or holding the catheter are maneuvers that may stabilize it and prevent spontaneous, uncontrolled movement and potential catheter-induced trauma.

This case report demonstrates the potential of spontaneous movement of the catheter due to excessive torque as a cause of coronary dissection and suggests the need for careful countermeasures when catheter twist is present.

\section{Conclusion}

This case report demonstrates the potential of spontaneous movement of the catheter due to excessive torque as a cause of coronary dissection and suggests the need for careful countermeasures when catheter twist is present.

\section{References}

1. Cameron J, Aroney C, Bett J (2000) Left main coronary artery dissection during coronary angioplasty or angiography treated by stent insertion without requirement for emergency bypass graft surgery. Aust N ZJ Med 30: 726-728. [Crossref]

2. Cheng C-I, Wu C-J, Hsieh Y-K, Chen Y-H, Chen C-J, et al. (2008) Percutaneous coronary intervention for iatrogenic left main coronary artery dissection. Int J Cardiol 126: $177-182$

3. Eshtehardi P, Adorjan P, Togni M, Tevaearai H, Vogel R, et al. (2010) Iatrogenic left main coronary artery dissection: incidence, classification, management, and long-term follow-up. Am Heart J 159: 1147-153. [Crossref]

4. Dunning DW, Kahn JK, Hawkins ET, O’Neill WW (2000) Iatrogenic coronary artery dissections extending into and involving the aortic root. Catheter Cardiovasc Interv 51: 387-393. [Crossref]

5. Curtis MJ, Traboulsi M, Knudtson ML, Lester WM (1992) Left main coronary artery dissection during cardiac catheterization. Can J Cardiol 8: 725-728. [Crossref]

6. Biel SI, Krone RJ (1984) Left coronary artery dissection with an amplatz-shaped catheter. The role of vigorous inspiration during contrast injection. Chest 86: 640-641. [Crossref]

7. López-Mínguez JR, Climent V, Yen-Ho S, González-Fernández R, Nogales-Asensio JM, et al. Structural features of the sinus of valsalva and the proximal portion of the coronary arteries: their relevance to retrograde aortocoronary dissection. Rev Esp Cardiol 59: 696-702. [Crossref]

8. Amano H, Kubo S, Osakada K, Miura K, Ohya M, et al. (2020) Clinical Outcomes and Angiographic Results of Bailout Stenting for Guide Catheter-Induced Iatrogenic Coronary Artery Dissection $\square$ - Impact of Stent Type. Circ J 84: 1746-1753. [Crossref]

9. Ammann P, Brunner-La Rocca HP, Angehrn W, Roelli H, Sagmeister M, et al. (2003) Procedural complications following diagnostic coronary angiography are related to the operator's experience and the catheter size. Catheter Cardiovasc Interv 59: 13-18. [Crossref]

10. Hayes SN, Kim ESH, Saw J, Adlam D, Arslanian-Engoren C, et al. (2018) Spontaneous Coronary Artery Dissection: Current State of the Science: A Scientific Statement from the American Heart Association. Circulation 137: e523-557. [Crossref]

11. Boyle AJ, Chan M, Dib J, Resar J (2006) Catheter-induced coronary artery dissection: risk factors, prevention and management. J Invasive Cardiol 18: 500-503. [Crossref]

Copyright: (C2021 Dogosh A. This is an open-access article distributed under the terms of the Creative Commons Attribution License, which permits unrestricted use, distribution, and reproduction in any medium, provided the original author and source are credited. 